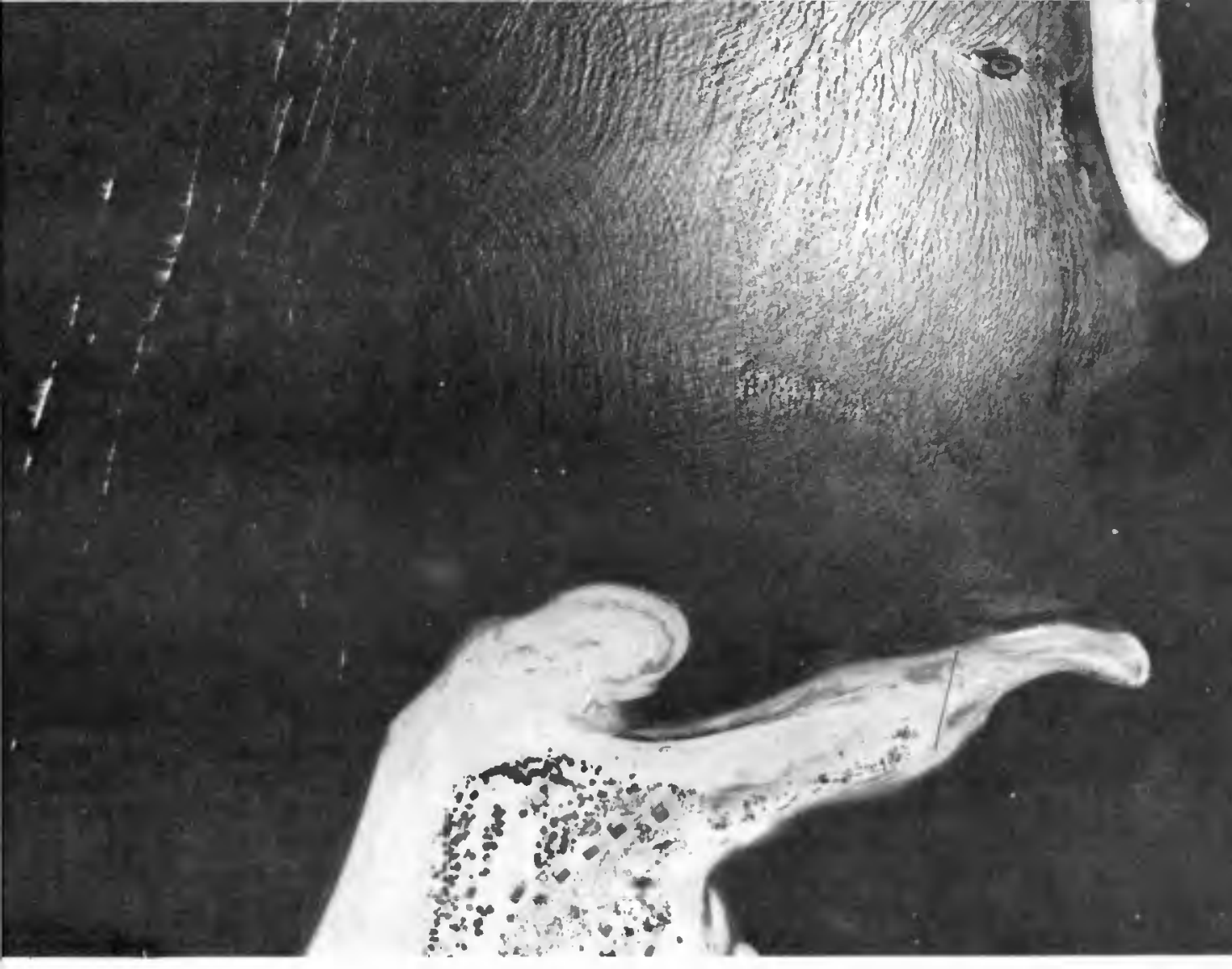

Samba Lagoon Inlet, Angola

Part 3

COASTAL STRUCTURES AND RELATED PROBLEMS

Aveiro Lagoon Inlet, Portugal

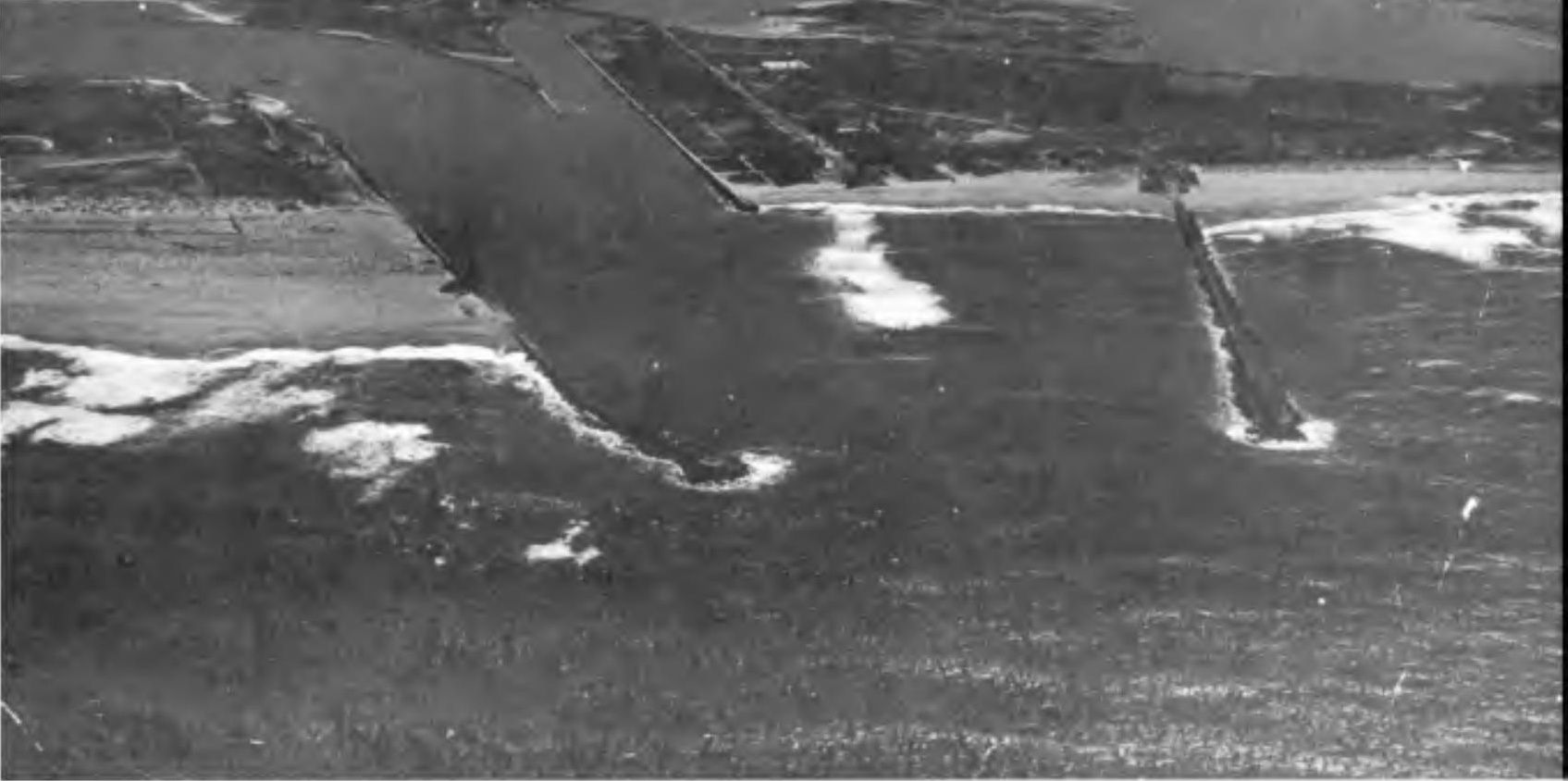




\title{
THE DYNAMIC RESPONSE OF OFFSHORE STRUCTURES TO TIME-DEPENDENT FORCES
}

\author{
William S. Gaithor, Graduate Student \\ and \\ David P. Billington, Professor \\ Department of Civil Engineering, Princeton University \\ Princeton, New Jersey
}

\section{INTRODUCTION}

This paper is addressed to the problem of structural behavior in an offshore environment, and the application of a more rigorous analysis for time-dependent forces than is currently used.

Design of pile supported structures subjected to wave forces has, in the past, been treated in two parts: (1) a static analysis based on the loading of a single wave, and (2) a dynamic analysis which sought to determine the resonant frequency by assuming that the structure could be approximated as a single-degree-of-freedom system. (Ref. 4 and 6) The behavior of these structures would be better understood if the dynamic nature of the loading and the many degrees of freedom of the system were included.

A structure which is built in the open ocean is subjected to periodic forces due to wind, waves, floating objects, and due occasionally to machinery mounted on the structure. To resist motion, the structure relies on the stiffness of the elements from which it is built and the restraints of the ocean bottom into which the supporting legs are driven.

Ocean wave forces vary in magnitude, direction, and elevation as they pass through a complete cycle. Figure $l$ (b) shows the forces of a wave of length $\lambda$ passing a simple bent. The legs of the bent, in the plane perpendicular to the wave crest, are spaced at a distance of $\lambda / 2$. Iog $A$ is then acted upon by a force to the right while $\operatorname{leg} B$ is forced in the opposite direction. If the legs were either an integer number of wave lengths apart, or extremely close together, they would be acted upon by approximately equal wave forces.

Even though the bent is a planar structure waves seldom approach in its plane or perpendicular to its plane. Figure 1 (a) shows the bent in plan with its plane rotated an angle $\gamma$ from the line of wave crests. Thus the forces on legs $A$ and $B$ are not only unequal and opposite but exsrt components of force both in the plane of the structure and also out of the plane. To treat this structure realistically it is necessary to formulate an analytic method which can accommodate all the variations in these timedependent forces. 


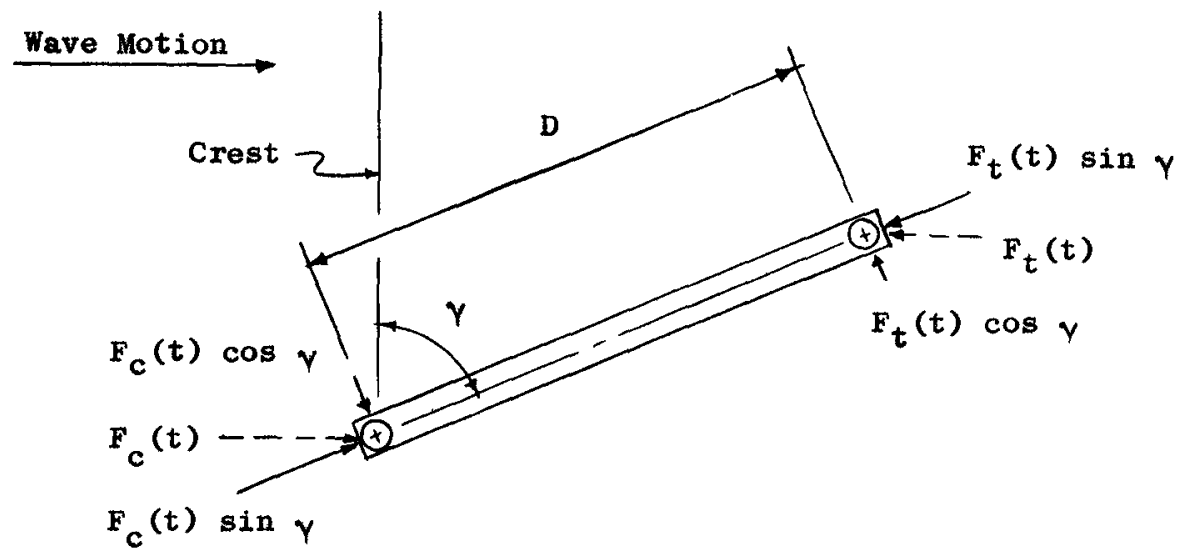

Figure I (a) Bent - Plan

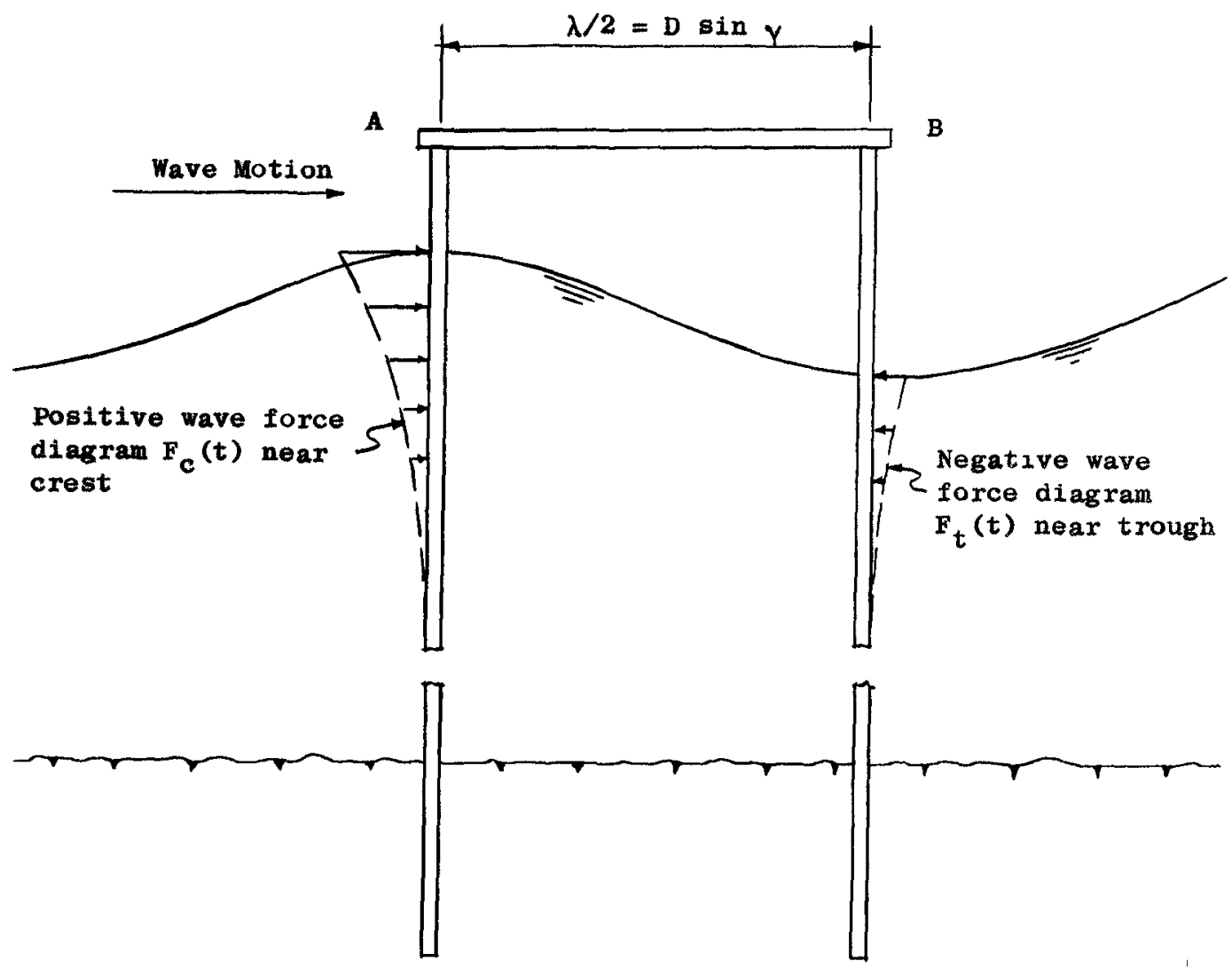

Figure I (b) Bent - Elevation 


\section{ANALYSIS}

For analysis the structural system is idealized as follows: First, the piles are assumed to be driven in the ocean bottom and fixed at a particular elevation. The analytic formulation in no way precludes the application of resisting soil forces as a function of deformation and time. Second, continuous members are assumed to be a series of discrete springs and masses so that a digital computer can be used for the solution. (Ref. 8) Third, the continuous force of a passing wave, represented by a known function of time, is idealized by breaking it into segments of depth L (see Fig. 2 (a)). The resultant of this force segment is denoted by $f_{n}(t)$.

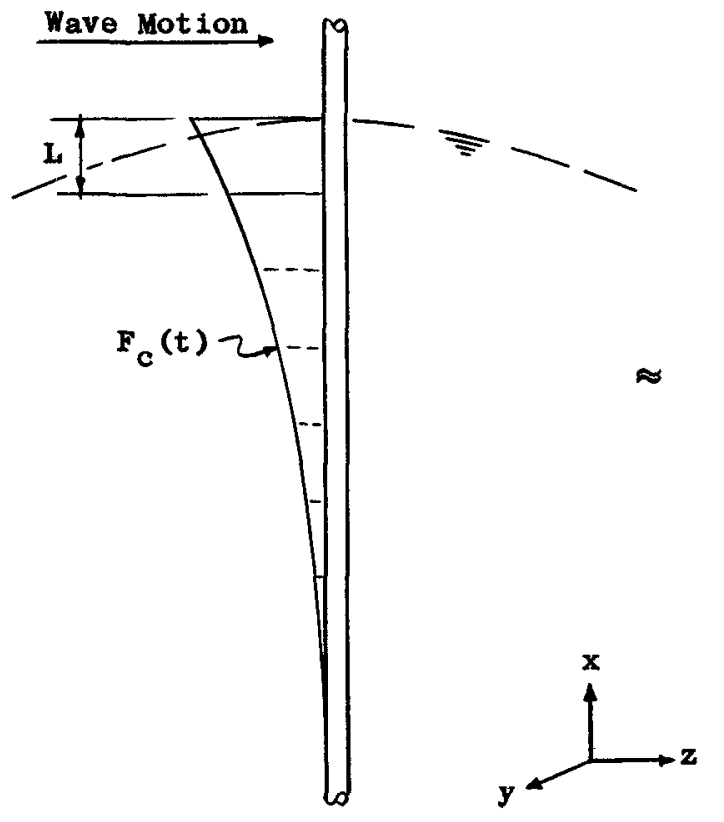

(a) Actual Pile

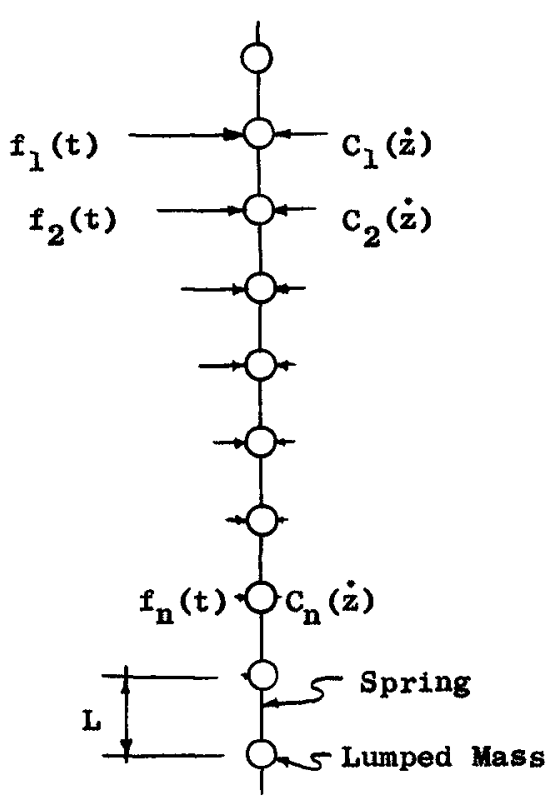

(b) Idealized Pile

Figure 2

Figure 2 (b) shows the idealized pile divided into a series of springs and masses. The distance between masses is also $L$ to correspond to the vertical increment of wave force selected. Acting externaliy on each mass is the viscous damping force of the water, $c_{n}(z)$. Non-linear damping can be included by considering the continuousiy varying value of $c_{n}$ as approximated by step values, each of which is constant for a short time. All further reference to beams or piles will assume the lumped mass idealization of Fig. 2 (b).

It is customary for vibrations texts (Ref. 9) to use the coordinate $x$ for the derivation of the equations of motion. To be consistent with later parts of this paper, the coordinate $z$ will be used here.

Further idealizations upon which this analysis is based are: (a) stress is proportional to strain, (b) small deflection theory, (c) all motion is 
measured from the position of static equilibrium (P.O.S.E.), and (d) one dimensional analysis.

\section{DIFFERENTIAL EQUATIONS OF MOTION}

Figure 3 shows a single-degree-of-f reedom system which consists of two basic parts. First, the spring $k$ and dashpot $c$ in parallel are equivalent to the spring of length $L$ in Fig. 2 (b). The dashpot in this location provides a means of expressing structural, or internal, damping. Second, $a$ mass $m$ is damped viscousiy and also forced by a steady-state periodic function. The need for this second dashpot is to provide a means to apply extermal viscous damping to the pile as shown in Fig. 2 (b) by $c_{n}(\dot{z})$. The forcing function $P$ cos it $i \frac{n}{8}$ analogous to $f_{n}(t)$ of Fig. 2 (b). With each mathematical expression tied to physical reality we may now apply $D^{\prime A l e m-}$ bert's Principle to Newton's Second Law and write the equation of motion as an equation of static equilibrium for the system of Fig. 3. (Ref. 9)

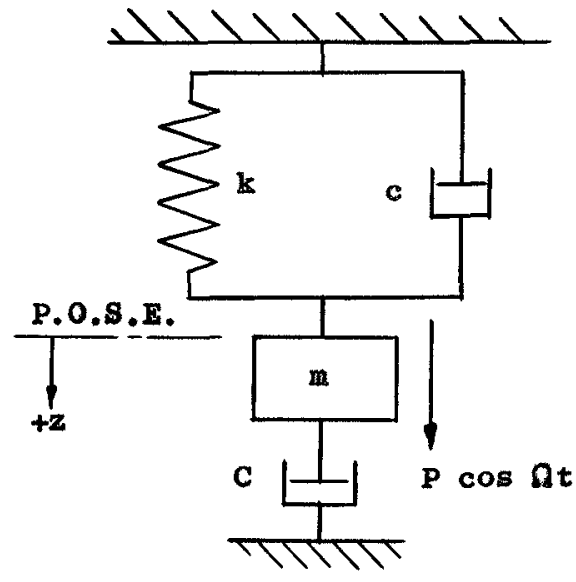

Figure 3 single-Degree-ofFreedom System with two Viscous Dampers

$$
m \ddot{z}+C \dot{z}+c \dot{z}+k z=P \cos \Omega t
$$

The forcing expression can be represented for convenience by the real part of the complex function

$$
P \cos \Omega t=\operatorname{Re}\left(P e^{j \Omega t}\right)
$$

where $j=\sqrt{ }-1$. For the offshore application our interest is focused on the response of the structure to a train of waves of approximately the same period. Mathematically then, we will seek only the steady-state soIution to Eq. (1) which is

$$
z=\operatorname{Re}\left(\bar{z} e^{j n t}\right)
$$

where the complex amplitude $\bar{z}$ represents the actual amplitude of motion made up of the vector sum of two components, the real and imaginary. For impulse loading (earthquake waves, blasts, or ship berthing) the transient solution could also be included. (Ref, 8) Differentiating Eq. (3) and substituting into Eq. (I), we obtain

or

$$
\left(-m \Omega^{2}+j c \Omega+j c \Omega+k\right) \bar{z} e^{j \Omega t}=p e^{j \Omega t}
$$

$$
-m \Omega^{2} \overline{\bar{z}}+j C \Omega \bar{z}+j c \Omega \bar{z}+k \bar{z}=P
$$

Through the use of complex notation the steady state solution, as given by Eq. (4), is easily obtained and the effect of each term remains apparent. 
Structural damping in homogeneous materials may be defined as a functizon of the forcing frequency $\Omega$ such that

$$
c=c(\Omega)=i \frac{\varepsilon}{\Omega}
$$

where $k$ is the spring constant and $\epsilon$ is a factor of proportionality which is charateristic of the material. (Ref. 2) By substituting Eq. (5) into Eq. (4) we obtain

$$
-m \Omega^{2} \bar{z}+j C \Omega \bar{z}+j k \varepsilon \bar{z}+k \bar{z}=P
$$

For analytic convenience the complex modulus $\bar{K}$ for structural damping can be formulated as

$$
\bar{k}(\Omega)=k+j \epsilon k=k(1+j \epsilon)
$$

For example in bending we have a flexibility term of the form $1 / \mathrm{k}=\mathrm{L}^{3} / 6 \mathrm{EI}$ where the elastic properties are expressed by $F$, or in the torsional case G. To handle these situations it is convenient to formulate an expression for the complex elastic modulus $\bar{E}$ and the complex shearing modulus $G$.

and

$$
\bar{E}=E(1+j \epsilon)
$$

$$
\bar{G}=G(1+j \epsilon)
$$

Where $\overline{\mathbf{E}}$ appears in the denominator as cited above, the imaginary portion is then moved to the numerator

$$
\frac{1}{k}=\frac{L^{3}}{6 E(1+j \epsilon) I} \frac{(1-j \varepsilon)}{(1-j \varepsilon)}=\frac{L^{3}(1-j \varepsilon)}{6 E I\left(1+\epsilon^{2}\right)}
$$

so that the imaginary part may be separated from the real in the matrix formulation.

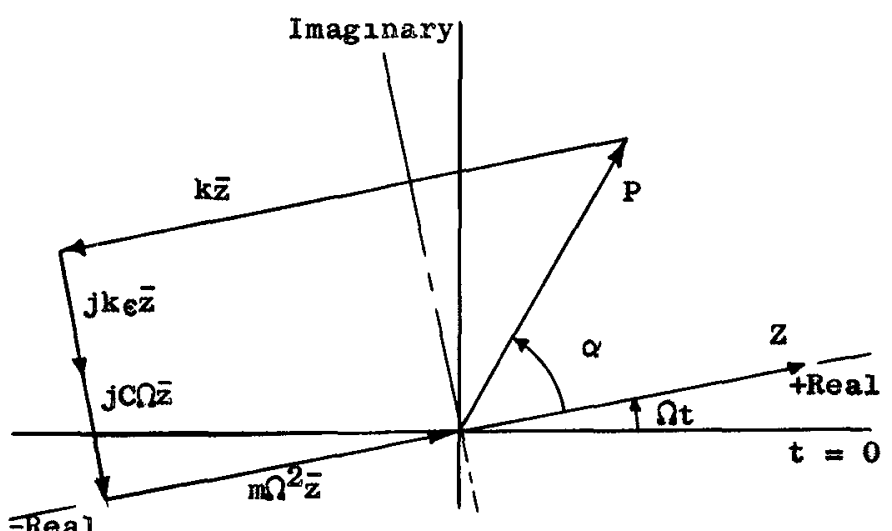

Figure 4 Vector Force Representation of Eq. (6) with Phase Angle $\alpha<90^{\circ}$
Figure 4 shows the vector relationship of the terms of Eq. (6). From the axis $t=0$ the entire vector force diagram (an Argand diagram, i.e. any diagram on the complex plane) is rotating at the constant angular velocity $\Omega t$. As the forcing frequency $\Omega$ moves toward a resonant frequency of the structure, $\alpha$ approaches $90^{\circ}$. When $\alpha$ $=90^{\circ}$ the externally applied force is devoted exclusively to opposing damping, both structural and external, while the spring force $k \bar{z}$ is equal 
and opposite to the inertia force $\mathrm{m}^{2} \overline{\mathrm{z}}$.

\section{MATRIX FORMULATION}

The equations required to describe the motion of each spring and each mass are formulated in matrix notation for concise explanation in this paper, and for systematic manipulation within the program for the digital computer. This section employs three matrix expressions: (1) the state vector, (2) the mass matrix, and (3) the field transfer matrix. The formulation of these types of matrices has been described in detail by pestel and Leckie. (Ref. 8)

The coordinate system used throughout this paper is shown in Fig. 5 and follows the right-hand rule.

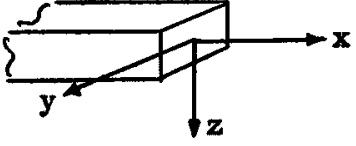

(a) Coordinate Axes

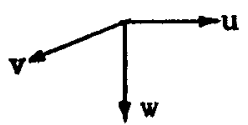

(b) Displacements

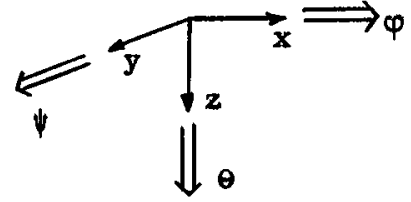

(c) Rotations

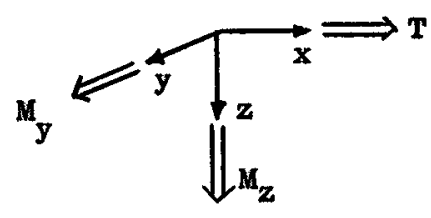

(d) Moments

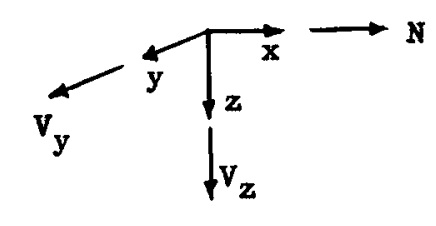

(e) Shears

Coordinate system

The centroidal axis, which in the cases studied here is taken always to coincide with the shear center of any member, will be the $x$-axis as shown in $\mathrm{Fig.5}$ (a).

Equation (6) contains both real and imaginary tems. However, instead of formulating matrices of complex numbers it is possible to partition all matrices in such a way that both real and imaginary terms may be treated as real and still remain separated. (Ref. 7) The following complex multiplication

$$
[\mathrm{A}][\mathrm{B}]=[\mathrm{C}]
$$

can be written in partitioned form as

$$
\left[\begin{array}{c:c}
R_{A} & -I_{A} \\
\hdashline I_{A} & R_{A}
\end{array}\right]\left[\begin{array}{c:c}
R_{B} & -I_{B} \\
\hdashline I_{B} & R_{B}
\end{array}\right]=\left[\begin{array}{c:c}
R_{A} R_{B}-I_{A} I_{B} & -R_{A} I_{B}-R_{B} I_{A} \\
\hdashline R_{B} I_{A}+R_{A} I_{B} & -I_{A} I_{B}+R_{A} R_{B}
\end{array}\right]=\left[\begin{array}{c:c}
R_{C} & -I_{C} \\
\hdashline I_{C} & R_{C}
\end{array}\right]
$$

where $\mathrm{R}$ represents real terms and I represents imaginary. The state Vector The state vector $\{z\}$ is so named because it gives the 
displacements and forces at any station along the beam. It is partitioned to separate real and imaginary parts and sub-partitioned to separate displacements and forces. Braces \{\} are used to denote a vertical column matrix but to use space more efficiently in this paper these will be written horizontally. Brackets [ ] are used for square matrices.

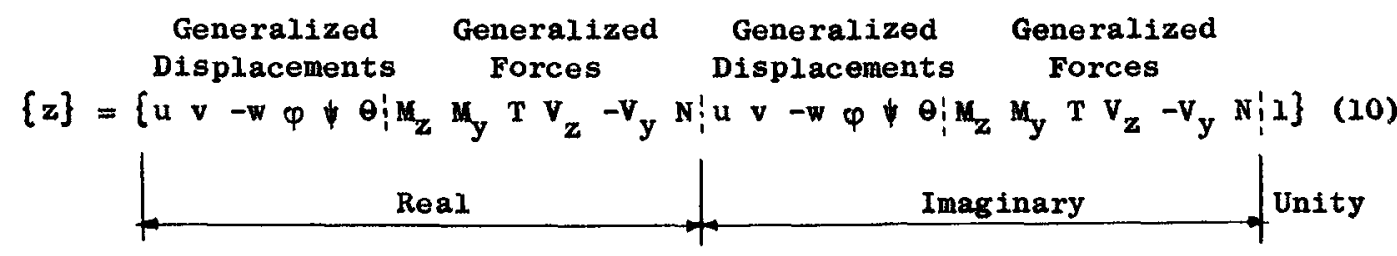

The significance of the unity term will become apparent in the formulation of the mass matrix.

The Mass Matrix Figure 6 shows a section of an arbitrary beam with the superscripts $R$ and $L$ denoting right and left.

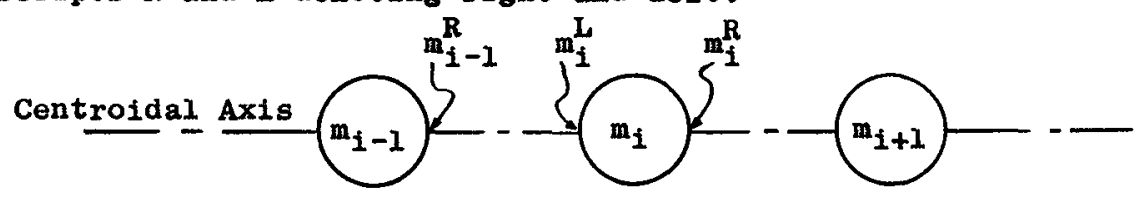

Figure 6 Portion of Arbitrary Beam

In Fig. 7 (a) a free-body diagram of mass $m_{i}$ in this beam is shown with the forces and displacements in the $z-x$ plane.

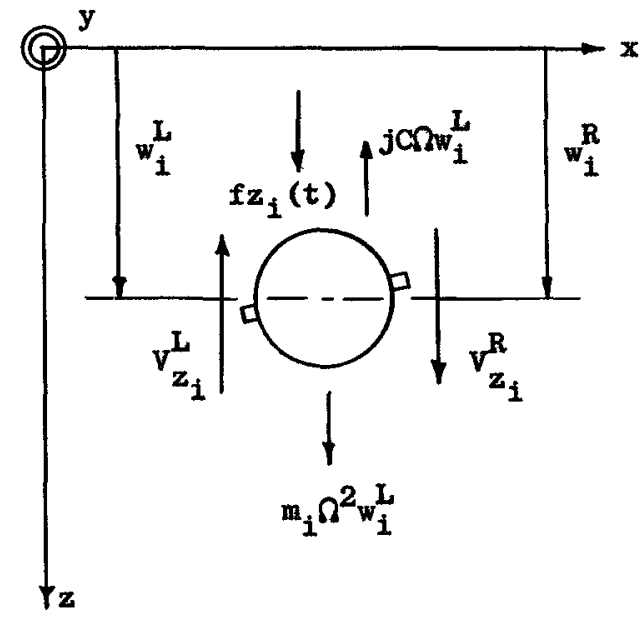

Figure 7 (a) Displacements and Forces - Mass $\mathrm{m}_{i}$

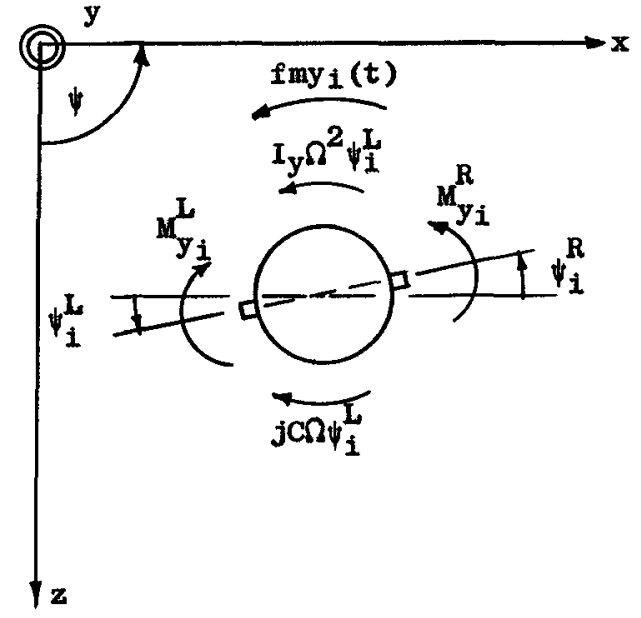

Figure 7 (b) Rotations and Moments - Mass $m_{i}$

Since the mass is considered lumped at an infinitesimally small point and is non-deformable, we may write the displacement equation as

$$
w_{i}^{R}=w_{i}^{L}
$$


and by summing forces in the $z$ direction

$$
v_{z_{i}}^{R}+m_{i} \Omega_{w_{i}}^{L}-v_{z_{i}}^{L}-j C \Omega w_{i}^{L}+f_{z_{1}}(t)=0
$$

we recognize three terms from Eq. (6) plus two shear terms.

Figure 7 (b) is a free-body diagram of the same mass $m_{i}$ as shown in Fig. 7 (a) but showing rotations and moments. The rotation equation is

$$
\psi_{i}^{R}=\psi_{i}^{L}
$$

and by summing moments about the $y$-axis

$$
\mathrm{M}_{y_{i}}^{R}+I_{y_{i}} \Omega^{2} \downarrow_{i}^{L}-M_{y_{i}}^{L}-j \cos \downarrow_{i}^{L}+f m_{y_{i}}(t)=0
$$

where $I_{y}=\int\left(x^{2}+z^{2}\right) d m$ and is called the mass moment of inertia.

By drawing four more free-body diagrams of mass $m_{i}$, two in the $x-y$ plane and two in the $y-z$ plane, eight more equations similar to Eqs. (II) through (14) can be written bringing the total to 12. If all equations are solved for the terms at the position to the right of $m_{1}$ as shown by $m_{i}^{R}$ in Fig. 6 , the mass matrix may then be written for mass $m_{i}$.

The state vector to the left of $m_{i}$ is $\{z\}_{i}^{L}$ and the state vector to the right is $\{z\}_{i}^{R}$, each containing the terms shown in Eq. (10). The $25 x$ 25 mass matrix [P] is then

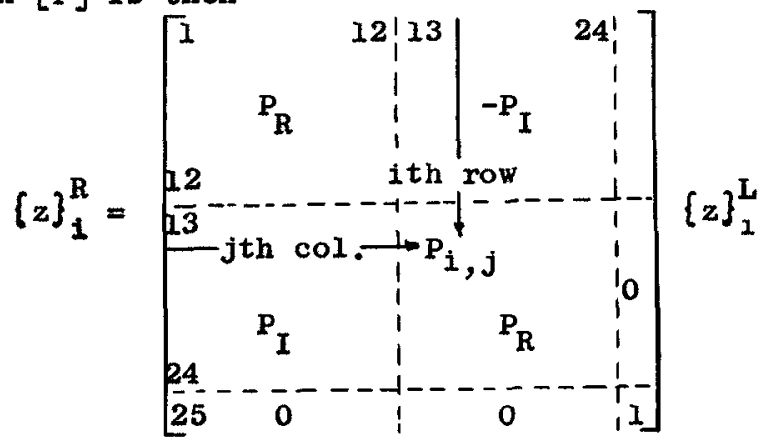

The constant term, fm. (t) of Eq. (14) is placed in the 25th column of [P]. The coefficient of one, whlch appears in the state vector of $\mathrm{Eq}$. (10) then has the effect of carrying the forcing function term along in the matrix operations. Table 1 lists the terms of matrix [P].

TABIE 1 Non-Zero Elements in the General Mass Martix Sub-Sections $\left[\mathrm{P}_{\mathbf{R}}\right],\left[-\mathrm{P}_{\mathbf{I}}\right]$, and column 25

$P_{R}$ (I thru 12, 1 thru 12) $=P_{R}(13$ thru 24, 13 thru 24)

$-P_{I}\left(1\right.$ thru 12, 13 thru 24) $=P_{I}(13$ thru 24, I thru 12)

\begin{tabular}{|c|c|c|c|c|c|c|c|c|}
\hline $\begin{array}{c}\text { Row } \\
(i)\end{array}$ & $\begin{array}{c}\text { Col } \\
(j)\end{array}$ & Term & $\begin{array}{c}\text { Col } \\
(j)\end{array}$ & Term & $\begin{array}{c}\text { CoI } \\
(j)\end{array}$ & Term & $\begin{array}{c}\text { CoI } \\
(j)\end{array}$ & Term \\
\hline 1 & 1 & 1.0 & & & & & & \\
2 & 2 & 1.0 & & & & & & \\
3 & 3 & 1.0 & & & & & & \\
\hline
\end{tabular}


TABLE I (cont.)

\begin{tabular}{|c|c|c|c|c|c|c|c|c|}
\hline $\begin{array}{l}\text { Row } \\
\text { (1) }\end{array}$ & $\begin{array}{l}\text { Col } \\
\text { (J) }\end{array}$ & $T \in \mathbf{r m}$ & $\mid \begin{array}{l}\text { Col } \\
(j)\end{array}$ & Term & $\mid \begin{array}{l}\mathrm{Col} \\
(\mathrm{J})\end{array}$ & Term & $\left|\begin{array}{cc}\mathrm{Col} \\
(\mathrm{j})\end{array}\right|$ & Term \\
\hline 4 & 4 & 1.0 & & & & & & \\
\hline 5 & 5 & 1.0 & & & & & & \\
\hline 6 & 6 & 1.0 & & & & & & \\
\hline 7 & 6 & $-I_{z} \Omega_{?}^{2}$ & 7 & 1.0 & 18 & $-\infty$ & 25 & $-f m_{z}(t)$ \\
\hline 8 & 5 & $-I_{y}^{z} \Omega_{n}^{2}$ & 8 & 1.0 & 17 & $-C \Omega$ & 25 & $-\operatorname{fm}_{v}(t)$ \\
\hline 9 & 4 & $-I_{x}^{y} \Omega_{0}^{2}$ & 9 & 1.0 & 16 & $-c \Omega$ & 25 & $-f m_{x}(t)$ \\
\hline 10 & 3 & $\mathrm{~m} \Omega_{2}^{2}$ & 10 & 1.0 & 15 & an & 25 & $-f_{z}(t)$ \\
\hline 11 & 2 & $\mathrm{~m} \Omega^{2}$ & II & 1.0 & 14 & c) & 25 & $f_{y}(t)$ \\
\hline 12 & 1 & $-m \Omega^{2}$ & 12 & 1.0 & 13 & $-\infty 2$ & 25 & $-\mathbf{f}_{x}^{y}(t)$ \\
\hline
\end{tabular}

The Field Transfer Matrix The section of beam between points $\mathrm{m}_{i-1}^{\mathrm{R}}$ and inf of Fig. 6 represents a spring connector of length L. A free-body dia-

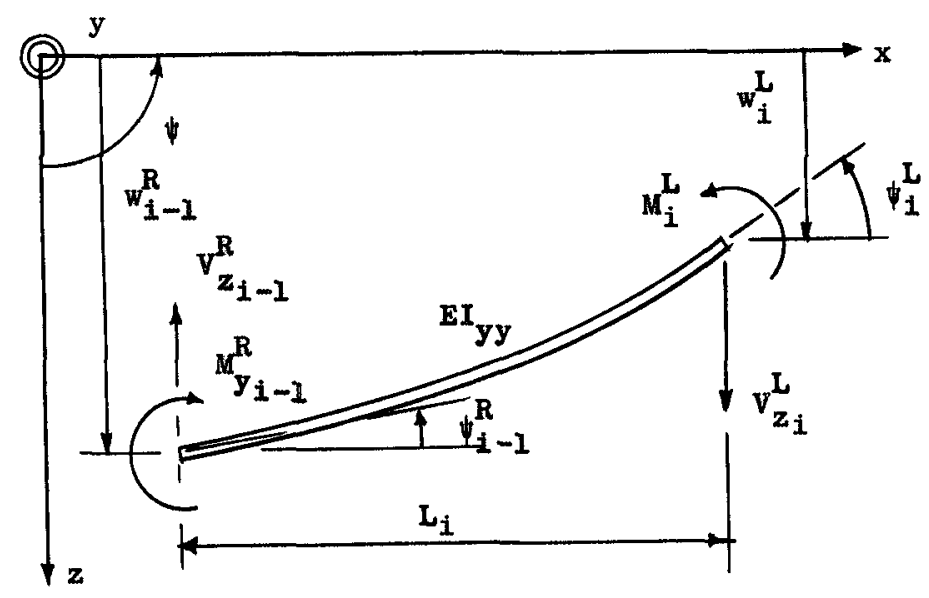

Figure 8 Displacements and Forces; Rotations and Moments

gram of this spring in the $z-x$ plane is shown in Fig. 8 from which the following equations are derived:

$$
\begin{gathered}
-w_{i}^{L}+w_{1-1}^{R}-L_{i} \psi_{i-1}^{R}-L_{i}^{2} M_{y_{i-1}}^{R} / 2 E I_{y y_{i}}-L_{i}^{3} v_{z_{i-1}}^{R} / 6 E I_{y y_{i}}=0 \\
\psi_{i}^{L}-\psi_{1-1}^{R}-L_{i} M_{y_{i-1}^{R}}^{R} / E I_{y y_{i}}-L_{i}^{2} v_{z_{i-1}}^{R} / 2 E I_{y y_{1}}=0 \\
M_{y_{i}}^{L}-M_{y_{i-1}}^{R}-L_{i} v_{z_{i-1}}^{R}=0 \\
-v_{z_{i}}^{L}-v_{z_{i-1}}^{R}=0
\end{gathered}
$$

Equations (16) and (17) relate the displacements and rotations at one end of the beam to the displacements and rotations at the other. Equation (18) is obtained by summing the moments and Eq. (19) by suming the shears shown in the free-body diagram.

By drawing free-body diagrams of the spring connectors in the $x-y$ and 
y-z planes, eight more equations can be written. Solving these equations for the terms to the left of mass $m_{1}$, the $25 \times 25$ field transfer matrix [F] can be written as

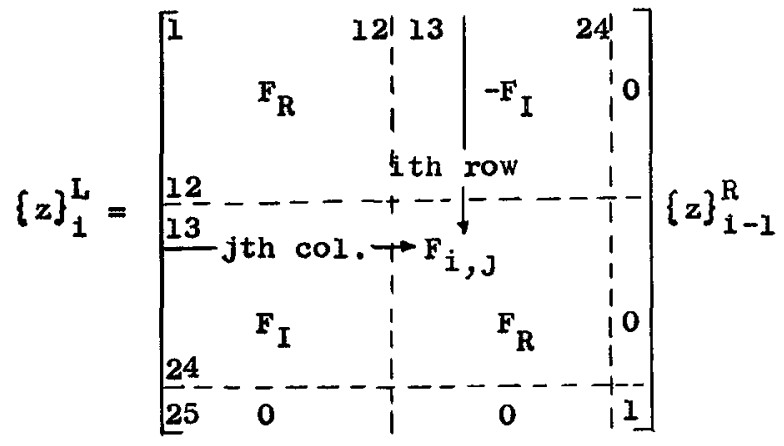

TABLE 2 (a) Non-Zero Elements in the General Field Matrix, Sub-Section $\left[F_{R}\right] ; F_{R}\left(1\right.$ thru 12, I thru 12) $=F_{R}(13$ thru 24, 13 thru 24)

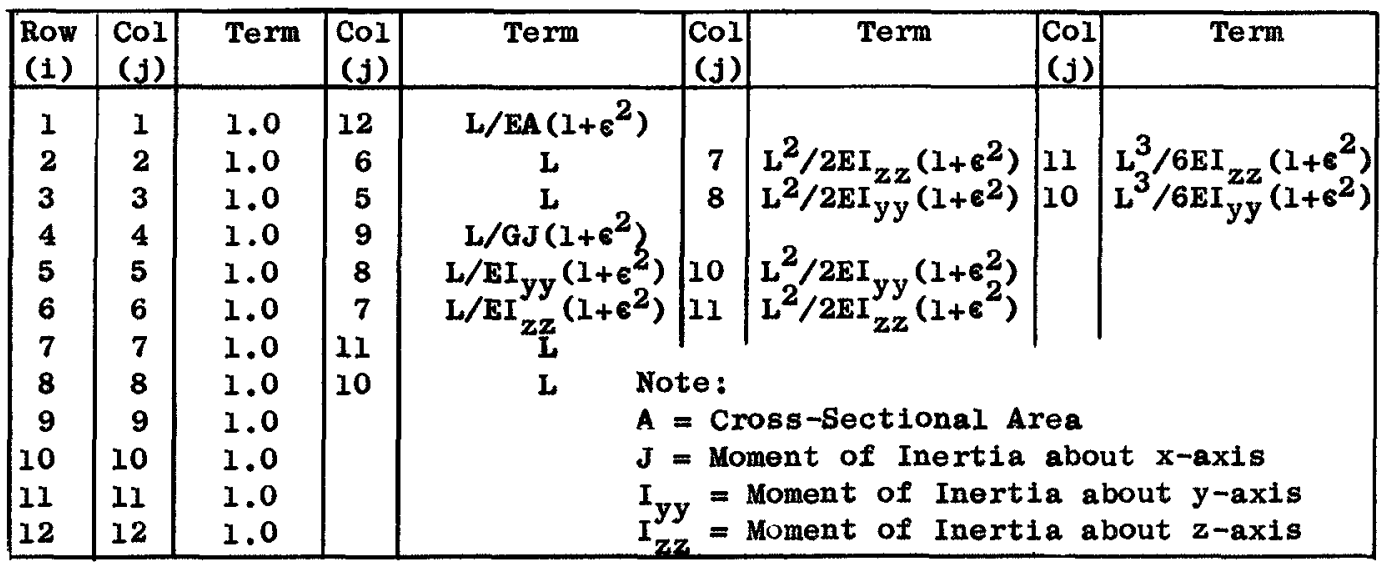

TABLE 2 (b) Non-Zero Elements in the General Field Matrix, Sub-Section $\left[F_{1}\right] ; F_{I}\left(13\right.$ thru 24, 1 thru 12) $=-\left[F_{I}\right](I$ thru 12, 13 thru 24)

\begin{tabular}{|c|c|c|c|c|}
\hline $\begin{array}{l}\text { Row } \\
\text { (1) }\end{array}$ & $\begin{array}{l}\mathrm{Col} \\
(\mathrm{j})\end{array}$ & Term & \begin{tabular}{|c|} 
Col \\
$(j)$
\end{tabular} & Term \\
\hline $\begin{array}{l}1 \\
2 \\
3 \\
4 \\
5 \\
6\end{array}$ & $\begin{array}{l}24 \\
19 \\
20 \\
21 \\
20 \\
19\end{array}$ & $\begin{array}{c}\epsilon \mathrm{E} / \mathrm{EA}\left(1+\epsilon^{2}\right) \\
\epsilon \mathrm{L}^{2} / 2 E I_{z z}\left(1+\epsilon^{2}\right) \\
\epsilon \mathrm{L}^{2} / 2 E I_{\mathrm{yy}}\left(1+\epsilon^{2}\right) \\
\epsilon \mathrm{L} / \mathrm{GJ}\left(1+\epsilon^{2}\right) \\
\epsilon \mathrm{L} / \mathrm{EI} \mathrm{yy}\left(1+\epsilon^{2}\right) \\
\epsilon \mathrm{L} / \mathrm{EI} \mathrm{IzZ}_{\mathrm{zz}}\left(1+\epsilon^{2}\right)\end{array}$ & $\begin{array}{l}22 \\
23\end{array}$ & $\begin{array}{l}\mathrm{CL}^{3} / 6 \mathrm{EI} \mathrm{zz}_{\mathrm{zZ}}\left(1+\epsilon^{2}\right) \\
\mathrm{CL}^{3} / 6 \mathrm{EI} \mathrm{yy}^{2}\left(1+\epsilon^{2}\right) \\
\mathrm{CL}^{2} / 2 \mathrm{EI} \\
\mathrm{CL}^{2} / 2 \mathrm{EI} \mathrm{yz}_{\mathrm{zz}}\left(1+\epsilon^{2}\right)\end{array}$ \\
\hline
\end{tabular}

Matrix Formulation for a Single Plie Figure 9 shows a single pile, fixed at the base and free at the upper end. A state vector $\{z\}_{A}$ may be written for the fixed base and a spring matrix $\left[F_{1}\right]$ for the first spring. The equation which relates the base at $A$ to the lower side of the first mass is

$$
\{z\}_{1}^{L}=\left[F_{1}\right]\{z\}_{A}
$$


Similarly the lower side of the first mass may be related to the upper side of the first mass by

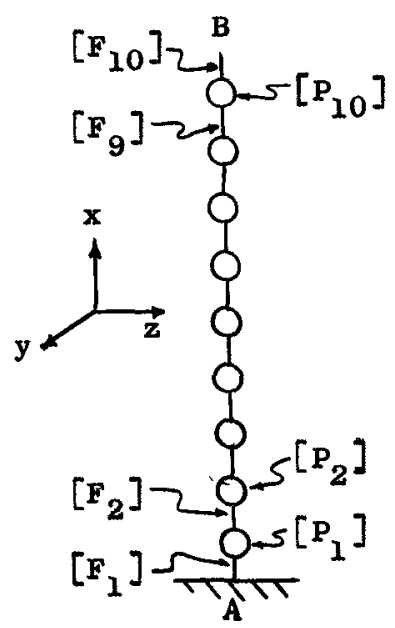

Figure 9 Cantilever Pile Idealized by 9 Lumped Masses

$$
\{z\}_{I}^{U}=\left[P_{I}\right]\{z\}_{1}^{L}
$$

By substituting Eq. (21) Into Eq. (22) the upper side of the first mass is related to the flxed base at $A$ by

$$
\{z\}_{1}^{U}=\left[P_{1}\right]\left[F_{1}\right]\{z\}_{A}
$$

This procedure is continued until the top of the pile is related to the base, giving the equation

or

$$
\begin{gathered}
\{z\}_{B A}=\left[F_{10}\right]\left[P_{9}\right]--\left[P_{1}\right]\left[F_{1}\right]\{z\}_{A} \\
\{z\}_{B A}=[A B]\{z\}_{A}
\end{gathered}
$$

Corner Transformation Matrix The mathematical model of a simple bent must include a method of transforming displacement and force information from a vertical member to the horizontal bent cap and then back to the second vertical pile. Considering the bent $\mathrm{ABCD}$ of $\mathrm{FIg}$. 10 and applying the right-hand-screw rule, the transformation around corner $B$ requires rotation about the $y$-axis through the angle $\psi=-90^{\circ}$. The state vector at the $B$ end of member $A B$ is

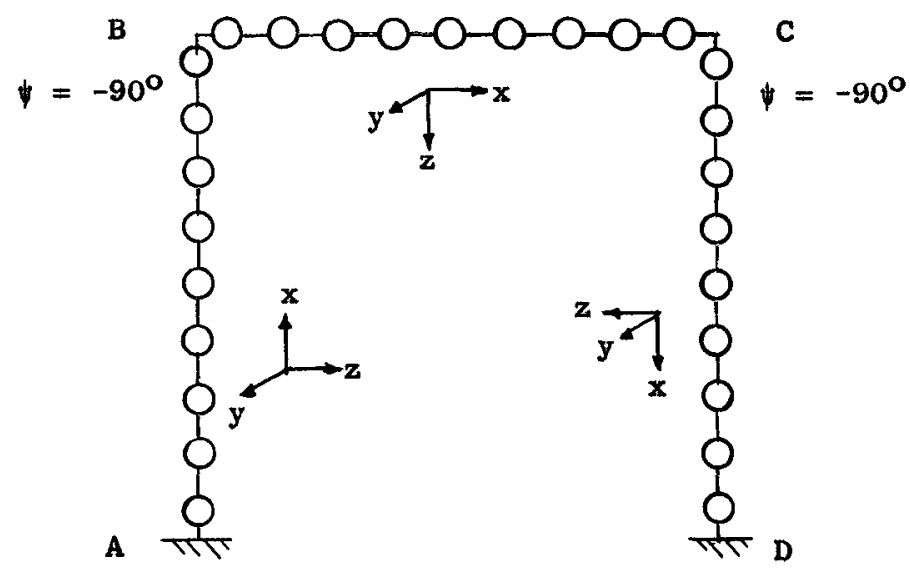

Figure 10 Bent Idealized by 27 Lumped Masses

$\{z\}_{\mathrm{BA}}$, the initial state vector in member $\mathrm{BC}$ is $\{\mathrm{z}\}_{\mathrm{BA}}^{\mathrm{T}}$, and the transformation matrix is [T]. Therefore,

$$
\{z\}_{\mathrm{BA}}^{\mathrm{T}}=[\mathrm{T}]\{\mathbf{z}\}_{\mathrm{AB}}
$$

which expanded into its partitioned form becomes 


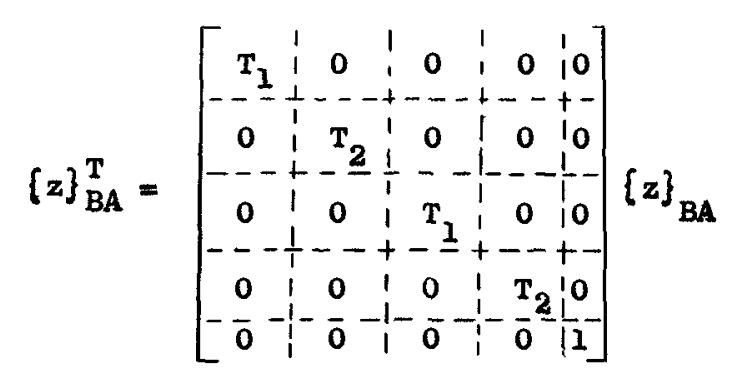

Submatrix $\left[T_{1}\right]$ transforms displacements and rotations

$$
\left[\mathrm{T}_{1}\right]=\left[\begin{array}{rrrrrr}
\cos \psi & 0 & \sin \psi & 0 & 0 & 0 \\
0 & 1 & 0 & 0 & 0 & 0 \\
-\sin \psi & 0 & \cos \psi & 0 & 0 & 0 \\
0 & 0 & 0 & \cos \psi & 0 & -\sin \psi \\
0 & 0 & 0 & 0 & 1 & 0 \\
0 & 0 & 0 & \sin \psi & 0 & \cos \psi
\end{array}\right]
$$

Similarly $\left[\mathrm{T}_{2}\right]$ transforms moments and shears

$$
\left[\mathrm{T}_{2}\right]=\left[\begin{array}{rrrrrr}
\cos \psi & 0 & \sin \psi & 0 & 0 & 0 \\
0 & 1 & 0 & 0 & 0 & 0 \\
-\sin \psi & 0 & \cos \psi & 0 & 0 & 0 \\
0 & 0 & 0 & \cos \psi & 0 & \sin \\
0 & 0 & 0 & 0 & 1 & 0 \\
0 & 0 & 0 & -\sin \psi & 0 & \cos \psi
\end{array}\right]
$$

Mathematical Model of Bent The bent of Fig. 10 was 1dealized by assuming nine masses per member, with each mass being allowed six degrees of freedom, or a total of 162 degrees of freedom for the structure. This bent was programmed and is to serve as an analytic and experimental example for the remainder of this paper.

The fixed base of leg $A$ was related to corner $B$ in a single matrix expression. Using Eq. (24) for comers $B$ and $C$ the entire bent can now be formulated in the single equation

or

$$
\{z\}_{D}=[C D][T][B C][T][A B]\{z\}_{A}
$$

$$
\{z\}_{D}=[U]\{z\}_{A}
$$

Expanding Eq. (25) into its partitioned form wo obtain

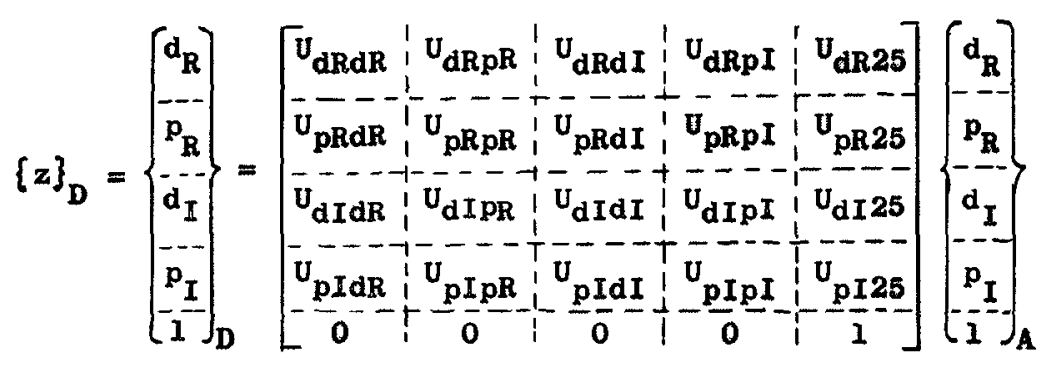


Equation (25) represents a series of 24 simultaneous equations (plus the identity $I=1$ ) which can be solved by applying the boundary conditions at points $A$ and $D$. At these points the displacements and rotations, denoted by $d_{R}$ for real and $d_{I}$ for imaginary, are zero due to the assumption of complete fixity, while the moments and shears, $p_{R}$ and $p_{I}$, are unknown. Next, extract from Eq. (25) the submatrices which have not been multiplied by zero displacement or rotation terms of $\{z\}_{A^{\prime}}$, and which are equated to zero terms of $\{z\}_{D}$.

$$
\left\{\begin{array}{c}
0 \\
\hdashline 0
\end{array}\right\}=\left[\begin{array}{c:c}
U_{d R p R} & U_{p R p I} \\
\hdashline U_{d I p R} & U_{d I p I}
\end{array}\right]\left\{\begin{array}{c}
p_{R} \\
p_{I}
\end{array}\right]_{A}\left[\begin{array}{l}
U_{d R 25} \\
\hdashline U_{d I 25}
\end{array}\right\}
$$

The forces $p_{R}$ and $p_{I}$ of $\operatorname{leg} A$ are found to be

$$
\left\{\begin{array}{c}
p_{R} \\
-p_{I}
\end{array}\right\}_{A}=\left[\begin{array}{l:l}
U_{d R p R} & U_{d R p I} \\
\hdashline U_{d I p R} & U_{d I p I}
\end{array}\right]^{-1}\left\{\begin{array}{l}
-U_{d R 25} \\
\hdashline-U_{d I 25}
\end{array}\right\}
$$

Electronic Computation The formulation of this analytic method in general terms presupposed its solution by an electronic computer. The matrix operations described above are grouped and written in FORTRAN as general subroutines.(Ref.3) Then a relatively short main program for any specific structure can be made up largely of commands which call subroutines.

In Eq. (23) the state vector for the upper side of mass one of leg $A B$ was expressed in terms of a mass matrix, a spring matrix, and the state vector at $A$ which is now known by Eq. (27). As matrix multiplication proceeds around bent $A B C D$, a matrix of coefficients is saved at each lumped mass, i.e. $\left[u_{n}\right]$.

and

$$
\{z\}_{1}^{U}=\left[P_{1}\right]\left[F_{1}\right]\{z\}_{A}=\left[U_{1}\right]\left\{z_{A}\right.
$$

etc.

$$
\{z\}_{2}^{U}=\left[P_{2}\right]\left[F_{2}\right]\left[P_{1}\right]\left[F_{1}\right]\{z\}_{A}=\left[U_{2}\right]\{z\}_{A}
$$

By successively retrieving coefficient matrices $\left[U_{1}\right],\left[U_{2}\right],---\left[U_{n}\right]$ and multiplying by the known state vector $\{z\}_{A}$, the entire $x$ esponse at each lumped mass may be computed and written out. This means that a numerical value will be computed for each term shown in the state vector of Eq. (10). By paring each real term with its corresponding imaginary term, a complex term may be re-established from which the phase angle $\alpha$ of Figs. 4 and 11 can be computed:

$$
\alpha=\arctan \frac{\text { Imaginary Component }}{\text { Real Component }}
$$

The analysis of an actual structure would begin with the selection of a frequency range over which the response is of interest. First, the static structural response to the maximum value of the forcing function is obtained by setting $\Omega=e=0$. Second, the entire frequency range is traversed in small increments and changes of sign of real terms are noted. Third, at a sign crange the response vectors are plotted on the complex 
plane, as shown in Fig. 11, to determine the maximum response. The points

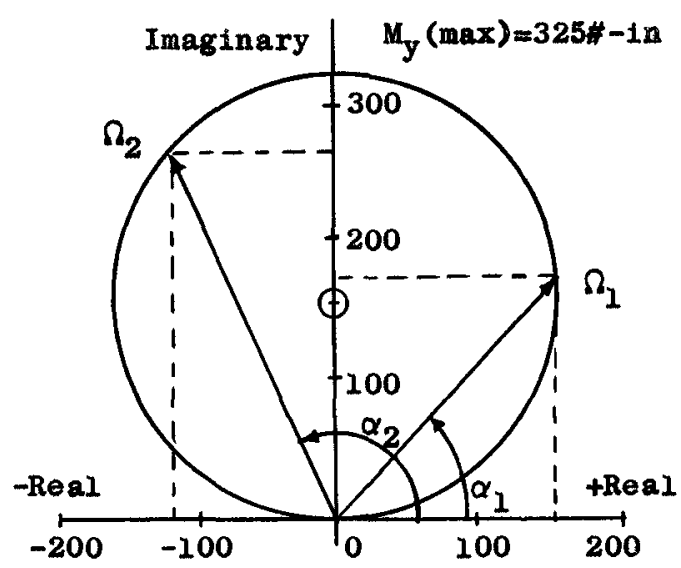

on the circle, $\Omega_{1}$ and $\Omega_{2}$ are found from the incremental approach. By using these two points and the origin, a circle can be constructed, the diameter of which is the value of the maximum response. (Ref. 1) Figure Il is the plot used to determine the magnitude of the first peak shown in Fig. 12 .

The bent $A B C D$ of $F i g .10$ was programmed in FORTRAN and run on an IBM 7094 computer, (Ref. 3) A single exciting force of 1.414 pounds was applied to the middie mass of $\operatorname{leg} A B$ in the $y-z$ plane at an angle of $45^{\circ}$ from the $z$ axis. This force resolves into 1.0 pound forces concurrent with

the $y$ and $z$ axes. The moments $H_{y}, M_{z}$, and $T$ at the base of $\operatorname{leg} A B$ were chosen to indicate the structural response through the entire frequency range. Figures 12 and 13 indicate the peaks at which resonant frequencies occur.

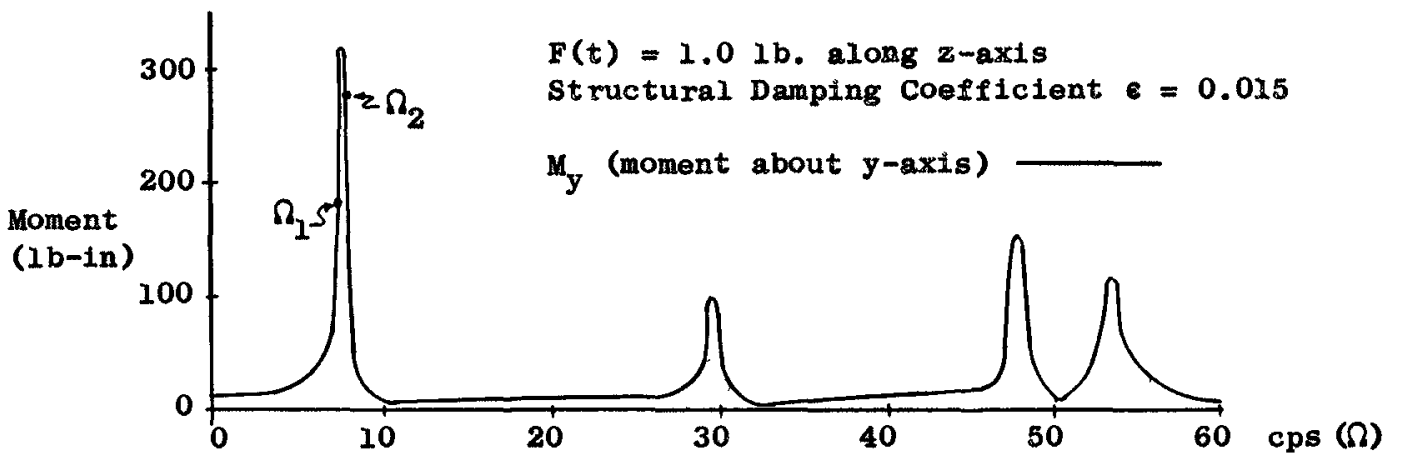

Figure $12 \mathrm{M}_{\mathrm{y}}$ at point $A$ with Forcing at Mid-Height of Leg $A B$

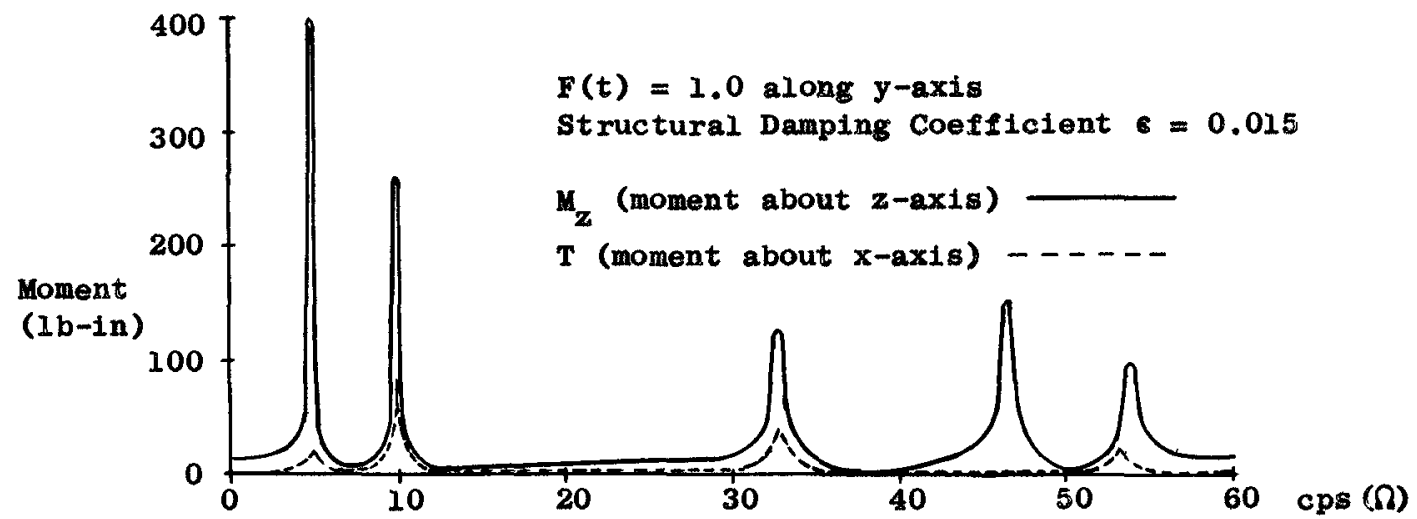

Figure $13 \mathrm{M}_{z}$ and $T$ at point $A$ with Forcing at Mid-Height of Leg $A B$ 
At each resonant peak a characteristic mode shape, or deformed shape of the structure, occurs which can be plotted from the computer output at each lumped mass. The maximum number of resonant frequencies which can be computed is equal to the number of degrees of freedom. Although the bent chosen for illustration was forced by a point load, the mode shapes and resonant frequencies would be similar if a series of point loads, which models a gravity wave function of the same frequency, were applied. The deformed shapes at each resonant frequency for in-plane loading are given by Figs. 14 and for out-of-plane loading by Figs. 15 .

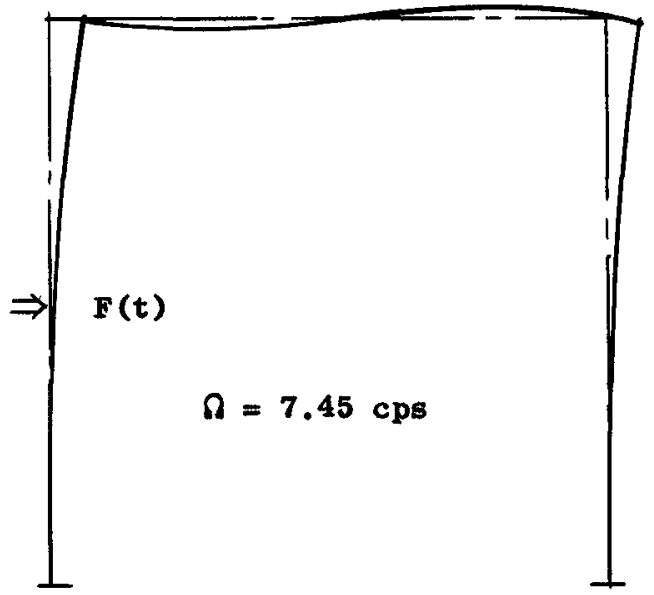

Figure 14 (a) Mode Shape for lst Resonant Frequency of Structure as a Whole

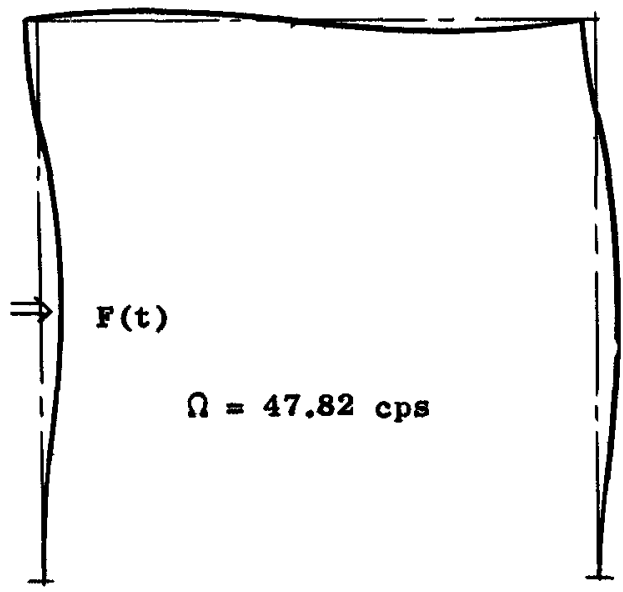

Figure 14 (c) Mode Shape for 3 rd Resonant Frequency of Structure as a Thole

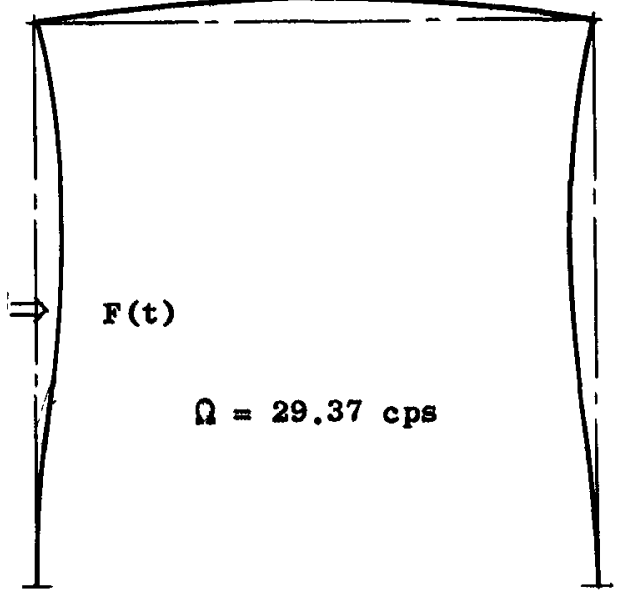

Figure 14 (b) Mode Shape for 2nd Resonant Frequency of Structure as a Whole

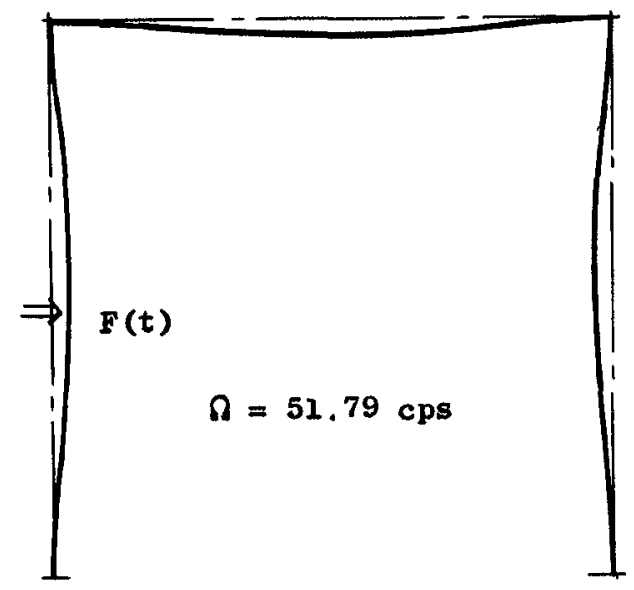

Figure 14 (d) Mode Shape for 4th Resonant Frequency of structure as a Whole 

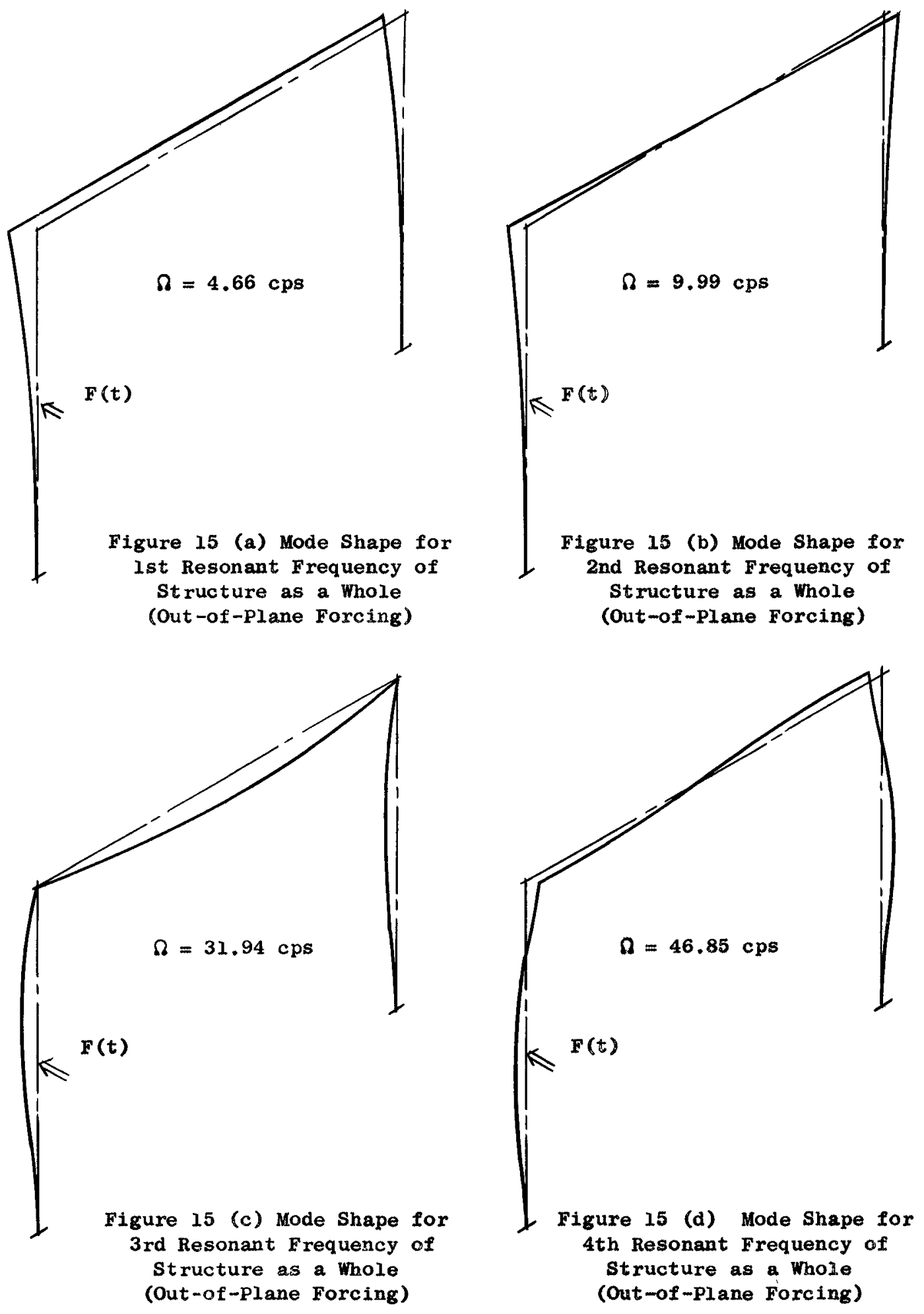


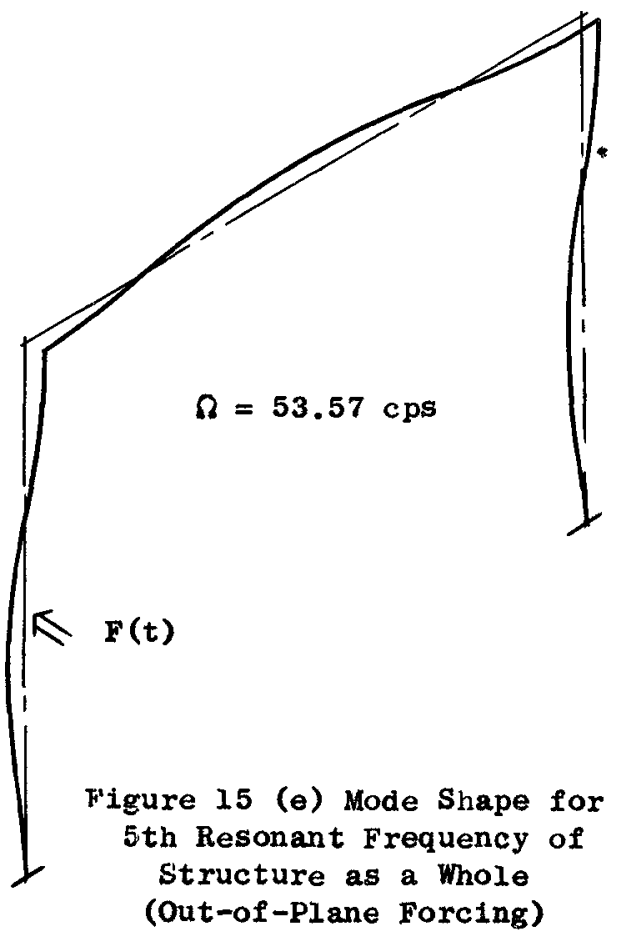

knownzing the mode shapes is of practical significance since the amplitude of resonant deformation is greatest. when the forces on each leg are putting energy into the structure. When a bent is deformed $1 n$ an ati-syms. (Figs. 14 (a), (c) and Figs. 15 (b), (d) forces on legs spaced an integer number of wave lengths apart are mutadiy rejuforcing. Similarly, wher a bent is deformed in a symmetric mode shape (Figs. 14 (b), (d) and Figs 15 (a), (c), (e)) Lorces on legs spaced an integer number of half-wave lengths apart add their effects. (At half-wave lengths the opposing forces are not necessarily at their maximum in all cases.(Ref, 5)) Thus the deLormed structures may be thought of in the same light as influence lines for resonant loading.

\section{EXPER IMENTAI, VERIFICATION}

'To test the validity of the analytic formulation a bent was constructed of $3-3 / 8^{\prime \prime}$ round steel rods each approximately $36^{\prime \prime}$ long. Full penetration welds were used at corners $B$ and $C$ and legs $A$ and $D$ were drilled and welded into a $15^{\prime \prime} \times 1 / 2^{\prime \prime} \times 4^{\prime}-0^{\prime \prime}$ steel base plate. In-plane and out-of-plane excitation was provided by an electro-magnetic shaker. Force input to the structure was measured by a crystal force gage, from which the signal was minimum at resonance points. The frequency of resonant oscillation was measured by a stroboscopic light which also provided a means of observing mode shapes for comparison with analysis.

TABLE 3 Summary: Calculated vs Experimental Resonant Frequencies

\begin{tabular}{|c|c|c|c|c|c|c|c|c|}
\hline \multirow[b]{2}{*}{ rig. } & \multicolumn{2}{|c|}{ In-Plane } & \multicolumn{2}{|c|}{ Out-of-Plane } & \multirow[b]{2}{*}{$\begin{array}{l}\text { High } \\
\text { cps }\end{array}$} & \multirow[b]{2}{*}{$\begin{array}{l}\text { Low } \\
\text { cps }\end{array}$} & \multirow{2}{*}{$\begin{array}{l}\text { Std. } \\
\text { Dev. } \\
\text { cps }\end{array}$} & \multirow{2}{*}{$\begin{array}{l}\text { Dis- } \\
\text { crep- } \\
\text { ancy }\end{array}$} \\
\hline & $\begin{array}{c}\text { Calc. } \\
\text { cps }\end{array}$ & $\begin{array}{r}\text { Exp. } \\
\text { cps }\end{array}$ & $\begin{array}{c}\text { Calc. } \\
\text { cps }\end{array}$ & $\begin{array}{l}\text { Exp. } \\
\text { cps }\end{array}$ & & & & \\
\hline $\begin{array}{l}14 \text { (a) } \\
14 \text { (b) } \\
14 \text { (c) } \\
14 \text { (d) }\end{array}$ & $\begin{array}{r}7.45 \\
29.37 \\
47.82 \\
51.79\end{array}$ & $\begin{array}{r}7.35 \\
29.27 \\
47.43 \\
51.80\end{array}$ & & & 0.01 & $\begin{array}{l}0.10 \\
0.10 \\
0.39\end{array}$ & $\begin{array}{l}0.07 \\
0.10 \\
0.25 \\
0.04\end{array}$ & $\begin{array}{l}1.4 \% \\
0.4 \% \\
0.8 \% \\
0.0 \%\end{array}$ \\
\hline $\begin{array}{ll}15 & \text { (a) } \\
15 & \text { (b) } \\
15 & \text { (c) } \\
15 & \text { (d) } \\
15 & \text { (e) }\end{array}$ & & & $\begin{array}{r}4.66 \\
9.99 \\
31.94 \\
46.85 \\
53.57\end{array}$ & $\begin{array}{r}4.62 \\
9.82 \\
31.75 \\
46.26 \\
53.58\end{array}$ & 0.01 & $\begin{array}{l}0.04 \\
0.17 \\
0.19 \\
0.59\end{array}$ & $\begin{array}{l}0.02 \\
0.03 \\
0.21 \\
0.18 \\
0.05\end{array}$ & $\begin{array}{l}0.9 \% \\
1.7 \% \\
0.5 \% \\
1.3 \% \\
0.0 \%\end{array}$ \\
\hline
\end{tabular}


Table 3 shows the comparison between calculated and experimental res-. onant frequencies for the nine modes investigated. The standard deviation was calculated from five experimental readings at each frequency. The discrepancy was computed from the average experimental frequency and the cal culated resonant frequency.

\section{COMPARISON TO SINGLE-DEGREE-OF-FREEDOM ANALYSIS}

For comparison bent $A B C D$ is assumed to have only one degree of freedom. The idealized structure would consist of an equivalent mass $M^{*}$, sup-

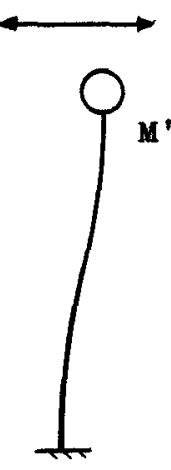

(a) In-Plane

Vibration

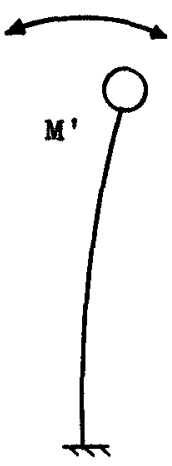

(b) out-of-Plane Vibration

Figure 16 Bent ABCD Idealized as a SingleDegree-of-Freedon Systen in Each Plane 4.42 cps compared to 4.66 cps from Table 3 , or $5 \%$ low. Of course no other frequencies can be computed from a single-degree-of-freedom system.

\section{CONCLUSIONS}

By the use of a lumped-mass system to describe a structure subjected to wave forces we may (1) apply wave forces of any magnitude, direction, and elevation directly to any part of the structure on which they act, (2) find all resonant frequencies in the range of the waves expected at the site, and (3) compute complete information on deflections, rotations, moments, and shears at all parts of the structure, even at resonance.

Use of the more rigorous analysis presented in this paper removes the three limitations imposed by the single-degree-of-freedom idealization:

(I) that wave forces cannot be applied direotly to the supporting piles, (2) only one resonant frequency can be obtained, and (3) its accuracy depends on an estimated equivalent mass.

\section{REF ERENCES}

1. Bisplinghoff, R.L., H. Ashley, and R.I. Halfman, Aeroelasticity. Addison-Wesley Publishing Co, Inc., Reading, Massachusetts, 1955 : 860 p. 
2. Fraeijs de Veubeke, B.M. Influence of internal damping on aircraft resonance. Manual on Aeroelasticity, v.1, ch.3, North Atlantic Treaty Organization Advisory Group for Aeronautical Research and Development. $1961: 38 \mathrm{p}$.

3. Gaither, W.S. Dynamic analysis of pile-supported offshore structures. Ph.D. Dissertation, Department of Civil Engineering, Princeton University. (Expected date of publication, August, 1964)

4. Harleman, D.R.F., W.C. Nolan, and V.C. Honsinger. Dynamic analysis of offshore structures. Proceedings of VIII Conference on Coastal thgineering, Mexico City. Councll on Wave Research, Richmond Fleld Station, Richmond, California, 1962.

5. Harleman, D.R.F, and R.G. Dean. Interaction of structures and waves. Estuary and Coastline Hydrodynamics, ch.H. Massachusetts Institute of Technology. $33 \mathrm{p}$.

6. Howe, R.J. The design of offshore drilling structures. Publication No. 8, Tech. Services Div., Shell Oil Co., Houston, Texas, 1954: $49 \mathrm{p}$.

7. Lanczos, C. Applied analysis. Prentice-Hall, Inc., Englewood Cliffs, New Jersey, 1956: 539p.

8. Pestel, E.C., and F.A. Leckie. Matrix methods in elastomechanics. McGraw-Hill Book Co., Inc., New York, 1963: 435p.

9. Thompson, W.T. Mechanical vibrations, Prentice-Hell, Inc., Englewood Cliffs, New Jersey, 1953: 252p. 